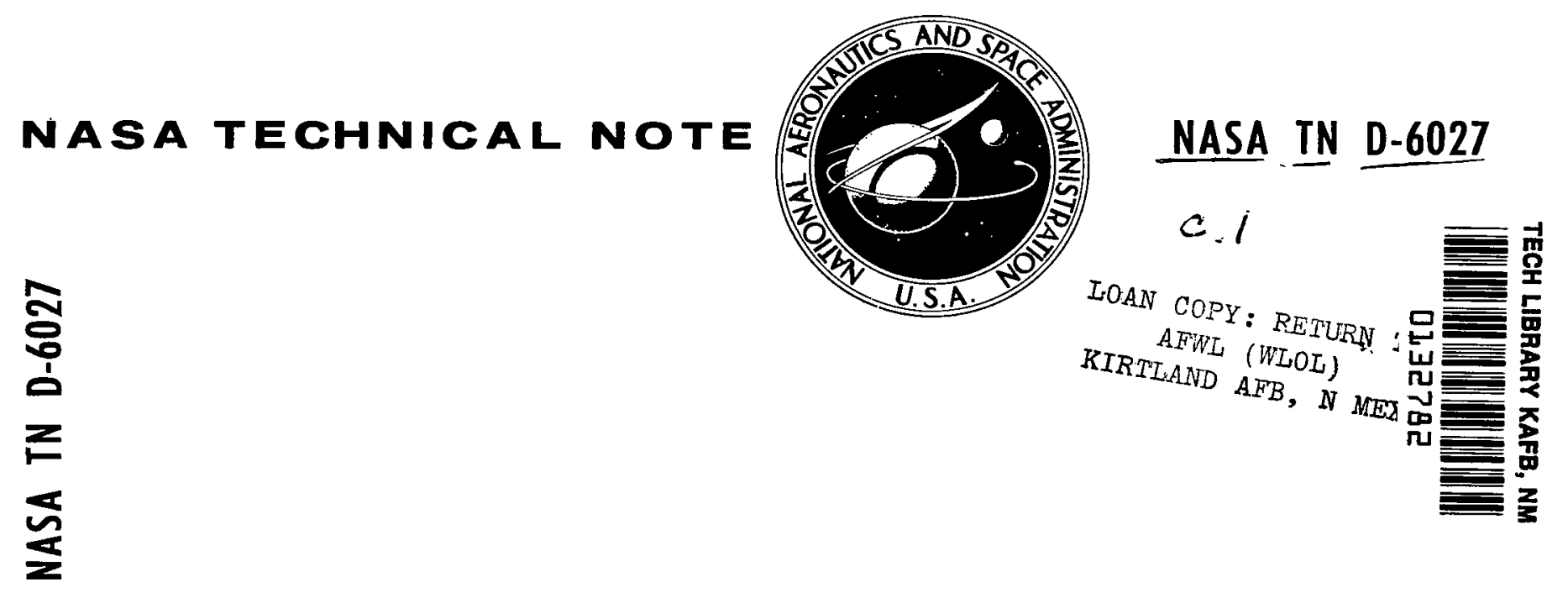

\title{
STABILITY OF PLANE POISEUILLE FLOW WITH HEAT TRANSFER
}

by Merle C. Potter and Edwin J. Graber, Jr.

Lewis Research Center

Cleveland, Obio 44135

national aeronautics and SPACE administration - WaShIngton, D. C. - october 1970 
1. Report No. NASA TN D-6027

4. Title and Subtitle STABILITY OF PLANE POISEUTLLE FLOW WITH HEAT TRANSFER

7. Author(s) Merle C. Potter, Michigan State Univ., East Lansing, Michigan; and Edwin J. Graber, Jr.. Lewis Research Center

9. Performing Organization Name and Address Lewis Research Center National Aeronautics and Space Administration Cleveland, Ohio 44135

12. Sponsoring Agency Name and Address

National Aeronautics and Space Administration Washington, D. C. 20546

15. Supplementary Notes

16. Abstract

The influence of heat transfer on the stability of a plane Poiseuille flow in a channel is under investigation. The primary liquid flow is affected by the heat transfer through the variation in viscosity with temperature. Additional viscosity gradient terms are included in a modified Orr-Sommerfeld equation and it is the presence of these terms which leads to a prediction of more unstable flows, for without the inclusion of these extra terms, the flow is stabilized. The results show that a temperature difference between the walls is always destabilizing.
2. Government Accession No.

3. Recipient's Catalog No.

5. Report Date

October 1970

6. Performing Organization Code

8. Performing Organization Report No. E-5818

10. Work Unit No.

720-03

11. Contract or Grant No.

13. Type of Report and Period Covered Technical Note

14. Sponsoring Agency Code
17. Key Words (Suggested by Author(s)) Hydrodynamic stability Poiseuille flow plane flow 19. Security Classif. (of this report) Unclassified
18. Distribution Statement

Unclassified - unlimited
20. Security Classif. (of this page) Unclassified
21. No. of Pages 12

$\$ 3.00$ 


\title{
STABILITY OF PLANE POISEUILLE FLOW WITH HEAT TRANSFER
}

\author{
by Merle C. Potter* and Edwin J. Graber, Jr. \\ Lewis Research Center
}

\section{SUMMARY}

The influence of heat transfer on the stability of a plane Poiseuille flow in a channel is analytically investigated. The primary liquid flow is affected by the heat transfer through the variation in viscosity with temperature. Additional terms resulting from the viscosity gradient are included in the development of a modified Orr-Sommerfeld equation. It is the presence of these terms which leads to a prediction of more unstable flows, for without their inclusion, the flow is stabilized. The results show that a temperature difference between the walls is always destabilizing and in particular a temperature difference between the walls of $100^{\circ} \mathrm{F}(55.6 \mathrm{~K})$ leads to a reduction in the critical Reynolds number from 7800 to 4600 .

\section{INTRODUCTION}

The linear stability characteristics of plane Poiseuille flow of a liquid between plates of fixed but different temperatures are investigated by the method of small disturbances. Particularly interesting is the influence of a temperature gradient on the minimum point (critical point) of the neutral stability curve. Since the viscosity of liquids is temperature dependent, the imposed temperature gradient creates a viscosity variation in the flowing fluid. This gradient subsequently causes additional terms to appear in the governing equation thereby altering the stability characteristics of the flow. To establish the importance of these additional terms, the stability equation is first solved with their inclusion and then with their omission. The primary velocity distribution used in both cases is the skew symmetric profile which results from the inclusion of the viscosity variation in the solution of the primary flow momentum equation.

Thomas (ref. 1), along with many others (e.g., ref. 2), has analytically determined the critical Reynolds number for isothermal Poiseuille flow in a channel. Thus

*Professor of Mechanical Engineering, Michigan State University, East Lansing, Michigan. 
in the present study the limiting case of equal wall temperatures $(\Delta \mathrm{T}=0)$ can be compared with Thomas' results.

Potter and Smith (ref. 3) introduced a skew-symmetric primary velocity profile into the Orr-Sommerfeld equation (stability equation neglecting a viscosity variation) for isothermal Poiseuille flow and established that a double critical point exists for this case. The profile used in their analysis, however, was taken from experimental results and was not analytically shown to correspond to the stability equation used. It was also concluded by Potter and Smith that a skew-symmetric primary velocity profile creates a more stable flow situation than does the symmetric velocity distribution (that is, the Reynolds number increases as the flow deviates from the symmetric velocity profile).

The present study was arranged to analytically produce a skew-symmetric velocity profile in water and then establish whether or not the corresponding stability equation yields a double critical point and results in a stabilizing effect as in Potter and Smith.

The governing equation and corresponding boundary conditions form an eigenvalue problem, and the eigenvalues being the Reynolds number, the wave number, and the wave speed. It is the eigenvalues forming the neutral stability curves that are of primary interest in this study. In particular, it investigates the influence of heating or cooling one wall on the minimum point of the neutral stability curve. The range of wall temperature differences considered is from $\Delta \mathrm{T}=0^{\circ} \mathrm{F}(0 \mathrm{~K})$ to $\Delta \mathrm{T}=200^{\circ} \mathrm{F}(111.1 \mathrm{~K})$ (the symbols are defined in the appendix).

\section{ANALYSIS}

\section{Primary Flow}

For steady two-dimensional flow of a viscous liquid flowing between heated parallel plates (see fig. 1), the $\mathrm{x}$-component of the momentum equation reduces to

$$
\frac{d}{d Y}\left(\mu \frac{d U}{d Y}\right)=\frac{d P}{d X}
$$

Neglecting viscous dissipation (see ref. 4), the energy equation yields the linear temperature profile

$$
\mathrm{T}=\left(\mathrm{T}_{2}-\mathrm{T}_{1}\right) \frac{\mathrm{Y}}{\mathrm{d}}+\mathrm{T}_{1}
$$

where $T_{2}$ and $T_{1}$ are the upper and lower plate temperatures, respectively, and $d$ is the distance between the plates. 
The viscosity relation used in this study is the conventional one for liquids, namely,

$$
\mu=c_{2} \mu_{0} \mathrm{e}^{\mathrm{c}_{1} / \mathrm{T}}
$$

where $c_{2}$ and $c_{1}$ are constants determined from viscosity-temperature curves and $\mu_{0}$ is the viscosity at the cool wall.

The equations are nondimensionalized by using

$$
\begin{gathered}
\mathrm{x}=\frac{\mathrm{X}}{\mathrm{d}}, \quad \mathrm{y}=\frac{\mathrm{Y}}{\mathrm{d}}, \quad \mathrm{u}=\frac{\mathrm{U}}{\mathrm{U}_{\mathrm{m}}}, \quad \mathrm{p}=\frac{\mathrm{P}}{\rho \mathrm{U}_{\mathrm{m}}^{2}} \\
\widetilde{\mu}=\frac{\mu}{\mu_{0}}, \quad \mathrm{R}=\frac{\mathrm{U}_{\mathrm{m}} \rho \mathrm{d}}{\mu_{0}}, \quad \overline{\mathrm{T}}=\frac{\mathrm{T}-\mathrm{T}_{1}}{\mathrm{~T}_{2}-\mathrm{T}_{1}}
\end{gathered}
$$

where $U_{m}$ is the average velocity. Equation (1) is, in dimensionless form,

$$
c_{2} \frac{d}{d y}\left\{\exp \left[\frac{c_{1}}{\left(T_{2}-T_{1}\right) y+T_{1}}\right] \frac{d u}{d y}\right\}=R \frac{d p}{d x}
$$

The solution of this equation, which satisfies the no-slip boundary conditions at the plates, is

$$
\begin{array}{r}
u(y)=\frac{R \frac{d p}{d x}}{2 a^{2} c_{2}}\left\{(a y+b)(a y-b+A-1) \exp \left(-\frac{1}{a y+b}\right)+b(b+1-A) \exp \left(-\frac{1}{b}\right)\right. \\
\left.+(A-1-2 b)\left[E\left(\frac{1}{b}\right)-E\left(\frac{1}{a y+b}\right)\right]\right\}
\end{array}
$$

where

$$
\mathrm{a}=\frac{\mathrm{T}_{2}-\mathrm{T}_{1}}{\mathrm{c}_{1}}
$$




$$
A=\frac{b=\frac{T_{1}}{c_{1}}}{(a+b)(b+1-a) \exp \left(-\frac{1}{a+b}\right)-b(b+1) \exp \left(-\frac{1}{b}\right)+(2 b+1)\left[E\left(\frac{1}{b}\right)-E\left(\frac{1}{a+b}\right)\right]}
$$

and $E(x)=\int_{x}^{\infty} e^{-t}(d t / t)$. In equation $(5) R(d p / d x)$ can be eliminated by the continuity relation $\int_{0}^{1} \mathrm{u}(\mathrm{y}) \mathrm{dy}=1$. As $\mathrm{T}_{2} \rightarrow \mathrm{T}_{1}, R(\mathrm{dp} / \mathrm{dx}) \rightarrow-12$ and $\mathrm{u} \rightarrow-6\left(\mathrm{y}^{2}-\mathrm{y}\right)$. Several of the velocity profiles are plotted in figure 1 . The values used for the constants $c_{1}$ and $c_{2}$ were $3233^{\circ} \mathrm{R}(1796.1 \mathrm{~K})$ and $1 / 445.9$, respectively.

\section{Stability Equation}

Let the stream function for an infinitesimal disturbance (a Tollmein-Schlichting wave) be given by

$$
\psi=\varphi(y) e^{i \alpha(x-c t)}
$$

where $\alpha$ is the wave number and $c=c_{r}+i c_{i}$, the complex wave speed. It can be shown that Squire's Theorem is applicable; hence the use of only two-dimensional disturbances. Using $\overline{\mathrm{u}}=\mathrm{u}(\mathrm{y})+(\partial \psi / \partial \mathrm{y})$ and $\overline{\mathrm{v}}=-\partial \psi / \partial \mathrm{x}$ as the perturbed velocity field in the Navier-Stokes equations results in, after nonlinear terms in $\partial \psi / \partial \mathrm{x}$ and $\partial \psi / \partial \mathrm{y}$ are neglected and the pressure is eliminated by cross-differentiation, the modified OrrSommerfeld equation (ref. 5)

$$
\begin{aligned}
(u-c)\left(\varphi^{\prime \prime}-\alpha^{2} \varphi\right)-\mathrm{u}^{\prime \prime} \varphi=-\frac{\mathrm{i} \tilde{\mu}}{\alpha \mathrm{R}}\left(\varphi^{\mathrm{iv}}-2 \alpha^{2} \varphi^{\prime \prime}+\alpha^{4} \varphi\right) \\
\\
\quad-\frac{\mathrm{i}}{\alpha \mathrm{R}}\left[2 \frac{\mathrm{d} \tilde{\mu}}{\mathrm{dy}}\left(\varphi^{\prime \prime \prime}-\alpha^{2} \varphi^{\prime}\right)+\frac{\mathrm{d}^{2} \tilde{\mu}}{\mathrm{dy}^{2}}\left(\varphi^{\prime \prime}+\alpha^{2} \varphi\right)\right]
\end{aligned}
$$

in which $\mathrm{R}=\mathrm{U}_{\mathrm{m}} \rho \mathrm{d} / \mu_{0}$. This equation differs from the usual Orr-Sommerfeld equations in that it contains the viscosity derivative terms. These terms are very significant for the study of liquids and must be retained. 
The boundary conditions representing the no-slip conditions at the walls are

$$
\varphi(0)=\varphi^{\prime}(0)=\varphi(1)=\varphi^{\prime}(1)=0
$$

The eigenvalue problem thus formed requires that

$$
\mathrm{c}_{\mathbf{i}}\left(\mathrm{c}_{\mathrm{r}}, \alpha, \mathrm{R}\right)=0
$$

if no growth or decay of the disturbance is allowed. The minimum Reynolds number from the neutral-stability curve representing the previous relation is the critical Reynolds number sought in this study. It will be a function of the $\Delta \mathrm{T}$ chosen between the two plates. The eigenfunction is not symmetric because of the skew-symmetric temperature imposed, hence one must use the whole channel in the analysis. Equation (7) with boundary conditions (8), the eigenvalue problem, must now be solved to yield the desired eigenvalues. A numerical technique, outlined in the following section, was chosen to solve the problem.

\section{Numerical Integration of the Modified Orr-Sommerfeld Equation}

The task of solving the modified Orr-Sommerfeld equation is made difficult by the presence of a very small coefficient of the highest order derivative of the order $10^{-4}$. The asymptotic method developed by Heisenberg (ref. 6) and improved by Lin (refs. 7 to 9 ) has been very popular but has certain limitations in addition to the difficulty involved by introducing the "critical" point. Numerical methods used to solve the OrrSommerfeld equation are proving to be quite successful. These methods generally require multiple precision as did that used by Thomas (ref. 1). However, an initial value scheme, requiring only single precision, has been devised by Kaplan (ref. 10). This scheme, used by Reynolds and Potter (ref. 11), will now be outlined.

Two linear independent solutions satisfying the lower wall boundary conditions must be combined to produce a solution satisfying the upper wall boundary conditions. One of these solutions grows very rapidly away from the wall, making it difficult to maintain two independent solutions during the numerical integration. To insure independency, Kaplan suggested suppressing the growing solution at each step in the calculations, that is, at each step a small multiple of the growing solution is subtracted from the behaved solution. The effect of the suppressed parts are later accounted for in the solutions. The two solutions thus formed are combined to satisfy the upper wall boundary conditions. 
The algorithm employed in the numerical integration is part of a predictorcorrector algorithm for fourth-order equations. However, the linearity of the equations eliminates the need for a predictor, and hence only the corrector equations are required. They are obtained by passing a third order polynomial through $\varphi^{\text {iv }}$ at four points, expressing the coefficients in terms of the values of the fourth derivative at the three backward points and the single forward point. This is then integrated to give $\varphi^{\prime \prime \prime}$ at the forward point in terms of the unknown fourth derivative, again to get $\varphi^{\prime \prime}$, and so forth. The resulting expressions for $\varphi$ and its derivatives are

$$
\begin{gathered}
\varphi_{1}=\varphi_{0}+\varphi_{0}^{\prime} \Delta+\varphi_{0}^{\prime \prime} \frac{\Delta^{2}}{2}+\varphi_{0}^{\prime \prime} \frac{\Delta^{3}}{6}+\frac{\Delta^{4}}{5040}\left(22 \varphi_{1}^{i v}+214 \varphi_{0}^{i v}-32 \varphi_{-1}^{i v}+6 \varphi_{-2}^{i v}\right) \\
\varphi_{1}^{\prime}=\varphi_{0}^{\prime}+\varphi_{0}^{\prime \prime} \Delta+\varphi_{0}^{\prime \prime} \frac{\Delta^{2}}{2}+\frac{\Delta^{3}}{720}\left(17 \varphi_{1}^{i v}+120 \varphi_{0}^{i v}-21 \varphi_{-1}^{i v}+4 \varphi_{-2}^{i v}\right) \\
\varphi_{1}^{\prime \prime}=\varphi_{0}^{\prime \prime}+\varphi_{0}^{\prime \prime \prime} \Delta+\frac{\Delta^{2}}{360}\left(38 \varphi_{1}^{i v}+171 \varphi_{0}^{i v}-36 \varphi_{-1}^{i v}+7 \varphi_{-2}^{i v}\right) \\
\varphi_{1}^{\prime \prime \prime}=\varphi_{0}^{\prime \prime \prime}+\frac{\Delta}{24}\left(9 \varphi_{1}^{i v}+19 \varphi_{0}^{i v}-5 \varphi_{-1}^{i v}+\varphi_{-2}^{i v}\right)
\end{gathered}
$$

where $\Delta$ is the mesh size and $\varphi_{\mathrm{n}}=\varphi\left(\mathrm{y}_{\mathrm{n}}\right)$. These expressions are substituted into the modified Orr-Sommerfeld equation yielding an equation in which $\varphi_{1}^{\text {iv }}$ is the only unknown. A similar scheme, based on a two-point fit, is used to start the calculation.

To use the previously outlined method, the eigenvalues must be known. If the eigenvalues are known only approximately, the upper wall boundary conditions cannot be satisfied exactly. To find the exact eigenvalues, the following iterative scheme is used. Let $\varphi^{\prime \prime \prime}(1)=0$ and choose $\varphi(1)$ as a test function $\mathrm{E}$. The object is to make $\mathrm{E}$ zero $\left(10^{-7}\right.$ will suffice). Fixing the wave speed $c\left(c_{i}=0\right)$, choose $\Delta \alpha$ and $\Delta R$ such that the positive-definite quantity $E \widetilde{E}$ is minimized $(\widetilde{E}$ is the complex conjugate of $E)$.

$$
\mathrm{E}=\mathrm{E}_{0}+\left(\frac{\partial \mathrm{E}}{\partial \alpha}\right)_{0} \Delta \alpha+\left(\frac{\partial \mathrm{E}}{\partial \mathrm{R}}\right)_{0} \Delta \mathrm{R}
$$

where $\partial \mathrm{E} / \partial \alpha$ and $\partial \mathrm{E} / \partial \mathrm{R}$ are found by using 0.01 percent changes in $\alpha$ and $\mathrm{R}$. Convergence to the exact values is quite rapid requiring only three or four passes. If a Control Data 3600 computer were used where each pass required 8 seconds, a neutral stability curve could be found in approximately 10 minutes if initial guesses were made carefully. 


\section{RESULTS AND CONCLUSIONS}

The primary velocity profiles corresponding to an imposed wall temperature difference of from $\Delta \mathrm{T}=0^{\circ} \mathrm{F}(0 \mathrm{~K})$ to $\Delta \mathrm{T}=200^{\circ} \mathrm{F}(111.1 \mathrm{~K})$ are given in dimensionless form in figure 1. Since the viscosity of liquids decreases with increasing temperature, the resultant velocity profiles became skewed as $|\Delta \mathrm{T}|$ increases; the maximum velocity is shifted towards the hotter wall.

Figure 2 shows that, if the viscosity gradient terms are neglected in the stability analysis, the resultant neutral stability curve is shifted to the right as $|\Delta \mathrm{T}|$ increases, thus indicating a more stable flow situation. This agrees with the results of Potter and Smith (ref. 3). In contrast, when the terms are accounted for, the flow becomes destabilized as $|\Delta \mathrm{T}|$ increases. It should also be noted that a double critical point did not appear in the neutral stability curve when the viscosity gradient terms were included in the equation. However, neglecting the viscous terms led to the appearance of an inflection point (or possibly a double critical point for other $\Delta T^{\prime}$ ) at a Reynolds number of approximately 32000 for $\Delta \mathrm{T}=100^{\circ} \mathrm{F}(55.6 \mathrm{~K}$ ) (fig. 2). Hence, even though the viscosity gradient terms are small, their inclusion is extremely important.

Figure 3 plots the variation of the critical Reynolds number with wall temperature difference $\Delta \mathrm{T}$. It can be seen that the temperature difference between the plates has a definite destabilizing effect; there is a 50 percent reduction in critical Reynolds number resulting from a $140^{\circ} \mathrm{F}(77.8 \mathrm{~K})$ temperature difference.

The curves for $\Delta \mathrm{T}=0^{\circ} \mathrm{F}(0 \mathrm{~K}$ ) (figs. 2 and 4) represent isothermal Poiseuille flow and agree with the accepted results of Thomas (ref. 1). Eigenfunctions are also plotted in figure 5 for $\Delta \mathrm{T}=0^{\circ} \mathrm{F}(0 \mathrm{~K})$ and for $\Delta \mathrm{T}=200^{\circ} \mathrm{F}(111.1 \mathrm{~K})$.

Lewis Research Center,

National Aeronautics and Space Administration,

Cleveland, Ohio, July 3, 1970 ,

720-03. 


\section{APPENDIX - SYMBOLS}

\begin{tabular}{|c|c|c|c|}
\hline A & constant & $\mathrm{U}_{\mathrm{m}}$ & average axial liquid velocity \\
\hline a & constant, $\left(\mathrm{T}_{2}-\mathrm{T}_{1}\right) / \mathrm{c}_{1}$ & $\mathrm{u}$ & dimensionless axial velocity, $\mathrm{U} / \mathrm{U}_{\mathrm{m}}$ \\
\hline b & constant, $\mathrm{T}_{1} / \mathrm{c}_{1}$ & $\overline{\mathrm{u}}$ & perturbed axial velocity \\
\hline c & complex wave speed, $c_{r}+i c_{i}$ & $\overline{\mathrm{V}}$ & perturbed transverse velocity \\
\hline$c_{1}, c_{2}$ & constants & $\mathrm{X}$ & axial coordinate \\
\hline$d$ & distance between plates & $\mathrm{x}$ & dimensionless axial coor dinate, \\
\hline $\mathrm{P}$ & static pressure of liquid & & $\mathrm{X} / \mathrm{d}$ \\
\hline $\mathrm{p}$ & dimensionless static pressure, & $\mathrm{Y}$ & transverse coordinate \\
\hline & $\mathrm{P} / \rho \mathrm{U}_{\mathrm{m}}^{2}$ & $\mathrm{y}$ & $\begin{array}{l}\text { dimensionless transverse coordi- } \\
\text { nate, } \mathrm{Y} / \mathrm{d}\end{array}$ \\
\hline $\mathrm{R}$ & Reynolds number, $\mathrm{U}_{\mathrm{m}} \rho \mathrm{d} / \mu_{0}$ & $\alpha$ & wave number \\
\hline$R_{c r}$ & critical Reynolds number & $\Delta$ & mesh size \\
\hline $\mathrm{T}$ & liquid temperature & $\mu$ & viscosity \\
\hline$\Delta \mathrm{T}$ & $\begin{array}{l}\text { wall temperature difference, } \\
\qquad \mathrm{T}_{2}-\mathrm{T}_{1}\end{array}$ & $\tilde{\mu}$ & dimensionless viscosity, $\mu / \mu_{0}$ \\
\hline $\mathrm{T}_{1}$ & lower wall temperature & $\mu_{0}$ & viscosity at $\mathrm{T}_{1}$ \\
\hline $\mathrm{T}_{2}$ & upper wall temperature & $\rho$ & density \\
\hline $\mathrm{t}$ & time & $\varphi$ & eigenfunction \\
\hline $\mathrm{U}$ & axial velocity of liquid & $\psi$ & stream function \\
\hline
\end{tabular}




\section{REFERENCES}

1. Thomas, L. H.: The Stability of Plane Poiseuille Flow. Phys. Rev., vol. 91, no. 4, Aug. 15, 1953, pp. 780-783.

2. Lin, Chia-Ch'iao: The Theory of Hydrodynamic Stability. Cambridge Univ. Press, 1955.

3. Potter, Merle C.; and Smith, Mahlon C.: Stability of an Unsymmetrical Plane Flow. Phys. Fluids, vol. 11, no. 12, Dec. 1968, pp. 2763-2764.

4. Poots, G.; and Rogers, M. H.: Laminar Flow Between Parallel Flat Plates, with Heat Transfer, of Water with Variable Physical Properties. Int. J. Heat Mass Transfer, vol. 8, Dec. 1965, pp. 1515-1535.

5. Wazzan, Ahmed R.; Okamura, T.; and Smith, A. M. O. : The Stability of Water Flow over Heated and Cooled Flat Plates. J. Heat Transfer, vol. 90, no. 1, Feb. 1968, pp. 109-114.

6. Heisenberg, W.: Ü̉ber Stabilität and Turbulenz von Flussigkeitsströmen. Ann. d. Physik, vol. 74, July 1924, pp. 577-627.

7. Lin, C. C.: On the Stability of Two-Dimensional Parallel Flows. Part I - General Theory. Quart. Appl. Math., vol. 3, no. 2, July 1945, pp. 117-142.

8. Lin, C. C.: On the Stability of Two-Dimensional Parallel Flows. Part II - Stability in an Inviscid Fluid. Quart. Appl. Math., vol. 3, no. 3, Oct. 1945, pp. 218-234.

9. Lin, C. C.: On the Stability of Two-Dimensional Parallel Flows. Part III Stability in a Viscous Fluid. Quart. Appl. Math., vol. 3, no. 3, Jan. 1946, pp. $277-301$.

10. Kaplan, Richard E.: The Stability of Laminar Incompressible Boundary Layers in the Presence of Compliant Boundaries. Rep. ASRL-TR-116-1, Massachusetts Inst. Tech., June 1964. (Available from DDC as AD-601779.)

11. Reynolds, W. C.; and Potter, Merle C.: Finite-Amplitude Instability of Parallel Shear Flows. J. Fluid Mech., vol. 27, pt. 3, Feb. 24, 1967, pp. 465-492. 



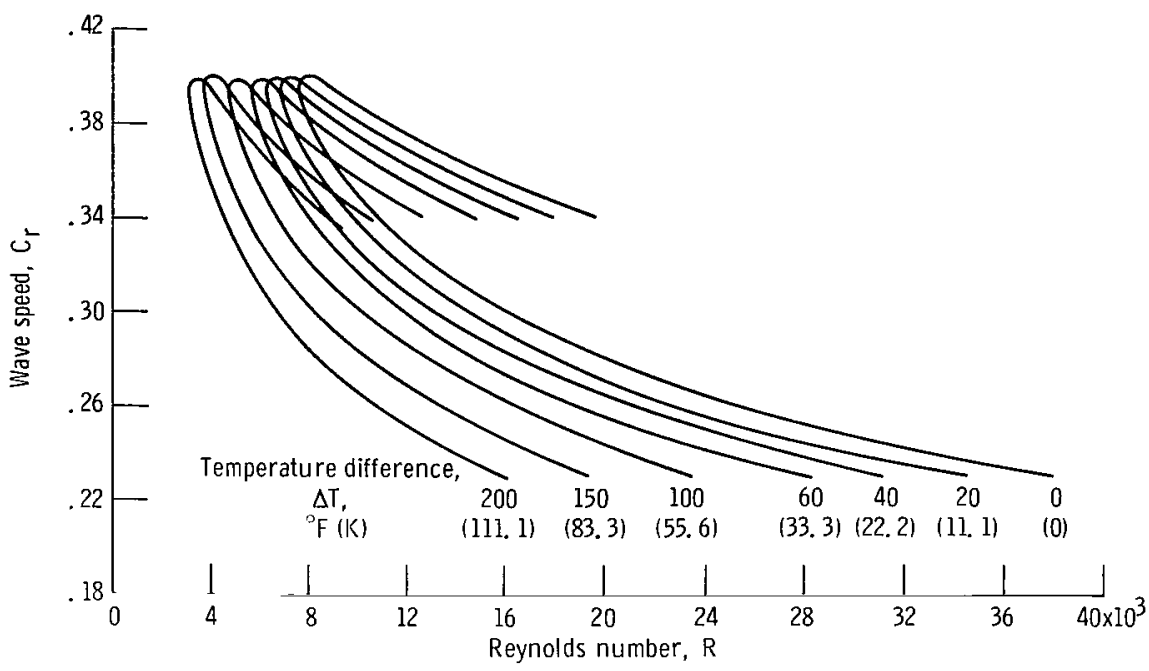

Figure 4. - Variation of wave speed with Reynolds number for various temperature differences $\Delta T$.

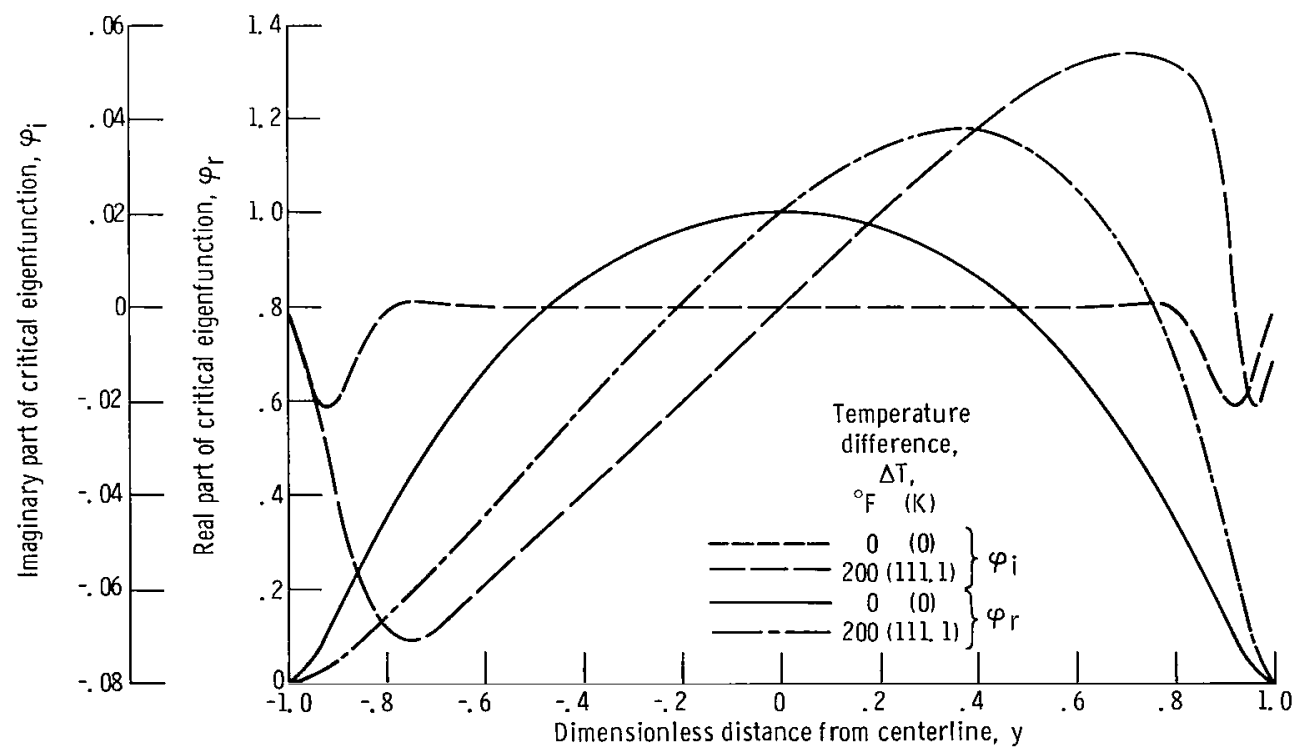

Figure 5. - Eigenfunctions at critical point 
Washington, D. C. 20546

OFFICIAL BUSINESS

FIRST CLASS MAIL

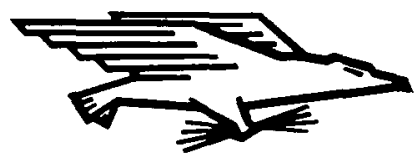

POSTAGE AND FEES PAID NATIONAL AERONAUTICS AND SPACE ADMINISTRATION
$70254 \quad 0090$

AIR FORCE WEAPONS LABORATORY/WLOL/

KIRTLAND AFB, NEW MEXICO 87117

ATT E. LOU BOWMAN, CHIEF, IECH. LIBRAR

POSTMASTER: If Undeliverable (Section 158

"The aeronatical and space activities of the United States shall be conducted so as to contribute. . . to the expansion of buman knowlsdge of phenomena in the atmosphere and space. The Administration shall provide for the widest practicable and appropriate dissemination of information concerning its activities and the results thereof."

- National Aeronautics and Space Act of 1958

\section{NASA SCIENTIFIC AND TECHNICAL PUBLICATIONS}

TECHNICAL REPORTS: Scientific and technical information considered important, complete, and a lasting contribution to existing knowledge.

TECHNICAL NOTES: Information less broad in scope but nevertheless of importance as a contribution to existing knowledge.

TECHNICAL MEMORANDUMS: Information receiving limited distribution because of preliminary data, security classification, or other reasons.

CONTRACTOR REPORTS: Scientific and technical information generated under a NASA contract or grant and considered an important contribution to existing knowledge.
TECHNICAL TRANSLATIONS: Information published in a foreign language considered to merit NASA distribution in English.

SPECIAL PUBLICATIONS: Information derived from or of value to NASA activities. Publications include conference proceedings, monographs, data compilations, handbooks, sourcebooks, and special bibliographies.

TECHNOLOGY UTILIZATION PUBLICATIONS: Information on technology used by NASA that may be of particular interest in commercial and other non-aerospace applications. Publications include Tech Briefs, Technology Utilization Reports and Notes, and Technology Surveys.

Details on the availability of these publications may be obtained from:

SCIENTIFIC AND TECHNICAL INFORMATION DIVISION

NATIONAL AERONAUTICS AND SPACE ADMINISTRATION

Washington, D.C. 20546 